Pol. J. Food Nutr. Sci., 2019, Vol. 69, No. 2, pp. 137-146

DOI: $10.31883 /$ pjfns-2019-105100 http://journal.pan.olsztyn.pl

Original research article

Section: Food Quality and Functionality

\title{
Composition of Anthocyanins in Colored Grains and the Relationship of Their Non-Acylated and Acylated Derivatives
}

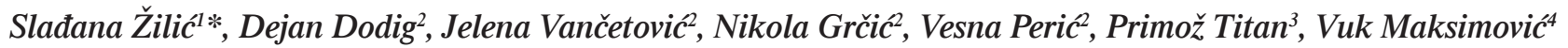 \\ ${ }^{1}$ Department of Food Technology and Biochemistry, Maize Research Institute, Slobodana Bajica 1, 11080 Zemun-Belgrade, Serbia \\ ${ }^{2}$ Breeding Department, Maize Research Institute, Slobodana Bajica 1, 11080 Zemun-Belgrade, Serbia \\ ${ }^{3}$ Research Genetics and Agrochemistry Ltd., Krog, Brodarska 27, 9000 Murska Sobota, Slovenia \\ ${ }^{4}$ Institute for Multidisciplinary Research, University of Belgrade, Kneza Višseslava 1, Belgrade, Serbia
}

Key words: acylated and non-acylated anthocyanins, blue and deep purple maize, black soybean, purple wheat

Colored grains are rich sources of anthocyanins that could play an important role in the prevention of various diseases associated with oxidative stress. Bearing in mind that cereals are widely grown crops, anthocyanins-rich colored grains could be used as a functional food ingredient that provides health benefits to a large part of human world's population. This study investigated composition and content of anthocyanins in the grain of blue popping maize, deep purple maize, purple wheat, and black soybean. The relationship of acylated and non-acylated forms before and after alkaline hydrolysis of anthocyanin extracts has been studied as well. Deep purple maize had the highest content of total anthocyanins reaching as much as $4988.90 \mathrm{mg} \mathrm{CGE} / \mathrm{kg} \mathrm{d.m}$. Ten anthocyanins were identified in blue popping maize, of which two are isomers of cyanidin-3-(malonylglucoside) and three of cyanidin-3-(dimalonyl- $\beta$-glucoside). Seven, nine, and three anthocyanins have been identified in the deep purple maize, purple wheat, and black soybean, respectively. Cyanidin derivatives were predominant and their acylated forms accounted for about $98,29,71$, and $0 \%$ of the total anthocyanins content in the grains, respectively. According to the study, acylated derivatives were completely degraded under the effect of highly alkaline $\mathrm{pH}$. However, at the beginning of their degradation they were transformed to their non-acylated parents.

The results could be useful to better understanding of the nature of anthocyanin in colored grains and, in that regard, their use for the derivation of food products with functional potential, as well as of natural dyes and pharmaceutical ingredients.

\section{INTRODUCTION}

Anthocyanins are natural pigments responsible for red, purple, and blue colors in the plant kingdom. They are common components of the human diet as they are present in many foods, fruits, and vegetables, especially in berries and red wine. Anthocyanins add not only colors to the food, but also potential health benefits to consumers because of their free radical scavenging capacity [Kähkönen \& Heinonen, 2003]. Health benefits associated with anthocyanins include enhancement of sight acuteness, treatment of various blood circulation disorders and neurodegenerative damages, anti-cancerous and anti-inflammatory properties, controlling diabetes, and possibly others due to their diverse action on various enzymes and metabolic processes [Giusti \& Wrolstad, 2003]. These qualities make anthocyanins attractive alternatives to synthetic dyes. However, anthocyanins incorporation to food is a certain challenge due to their low stability regarding the factors such as light, oxygen, temperature, and $\mathrm{pH}$. The same applies to their fate in the digestive tract and their bioavailability.

\footnotetext{
* Corresponding Author: Tel.: +381 113756 704; Fax: +381 113754 994; E-mail: szilic@mrizp.rs (S. Žilić)
}

According to recent data, almost 1000 anthocyanins have been identified in nature [Trouillas et al., 2016]. It is very rare that natural anthocyanins exist in aglycon form (as anthocyanidins). There were 31 anthocyanidins found in plants of which only six: cyanidin (Cy), delphinidin (Dp), pelargonidin $(\mathrm{Pg})$, peonidin $(\mathrm{Pn})$, malvidin $(\mathrm{Mv})$, and petunidin $(\mathrm{Pt})$, are widespread and usually found in fruits and vegetables [Andersen \& Jordheim, 2010]. According to the study of Kong et al. [2003], their distribution is: Cy 50\%, Dp 12\%, Pg 12\%, Pn 12\%, Mv 7\%, and Pt 7\%. Mostly, natural anthocyanins are present as various glycosides of $\mathrm{Cy}, \mathrm{Dp}, \mathrm{Pg}, \mathrm{Pn}$, $\mathrm{Mv}$, and Pt differing from each other by the successive addition of one more hydroxyl group at 3', 4', and at 5' that can be methylated. Among the 539 anthocyanins reported to be identified in a review article by Andersen \& Jordheim [2010], 97\% are glycosidated. In addition to the differences in the aglycone structure and glycosylation, anthocyanins differ in acylation moieties. The sugar residues can be acylated by aliphatic acids or by aromatic acids [Giusti \& Wrolstad, 2003]. Generally, they are linked to sugar in its 6- or 3-position but other substitutions are also present counting di-, trior poly- acyl substitution [Cortez et al., 2017]. Malonic acid and $p$-coumaric acid are the most frequent aliphatic and aromatic acyl groups, respectively. By 2010, out of the total 
number of the reported anthocyanins with properly identified structures, $65 \%$ of them were acylated, whereby acylation with phenolic acids was 1.5 more frequent than with aliphatic acids [Andersen \& Jordheim, 2010]. However, there are dissimilar results of such modifications on anthocyanins stability. Giusti \& Wrolstad [2003] reported that acylated anthocyanins (mostly di- or poly-acylated) possessed higher color stability to $\mathrm{pH}$ changes (from weakly acidic to slightly alkaline). Similar observations have been made by Torskangerpoll \& Andersen [2005] at pH 1.1 to 10. Further, Zhao et al. [2017] provided an overview of numerous studies, which confirmed that anthocyanin glycosyl acylation typically increased in vitro and in vivo chemical stability of acylated anthocyanins. However, unlike the above-mentioned reports in the literature, Luna-Vital et al. [2017] reported that the malonyl glycoside forms of the anthocyanins were more susceptible to degradation caused by time and $\mathrm{pH}$ than the non-acylated forms. In addition, neither the malonoyl derivative in purple corn nor the coumaroyl derivative in grape pomace showed enhanced stability at $\mathrm{pH} 3$ and 4 compared to their non-acylated parents [West \& Mauer, 2013]. According to results of Mora-Rochín et al. [2016], nixtamalization processing increased the relative percentage of glycosylated anthocyanins at alkaline $\mathrm{pH}$ and decreased the acylated anthocyanins. It has been established that differences in hydroxylation, methoxylation, glycosylation, and acylation patterns of anthocyanins had a critical impact on its color and antioxidant capacity, and, in this connection, on their health-beneficial effects expression in human body. Thus, in vitro activity of anthocyanidins in preventing the oxidation of human LDL decreased in the order delphinidin $=$ cyanidin $>$ malvidin $>$ peonidin $>$ pelargonidin $>$ pe tunidin, while glycosylation altered the activity order. Overall, glucosylated forms were less active than free forms in LDL suspensions [Kähkönen \& Heinonen, 2003]. The same authors state that the quality of the sugar substituent affected the activity of anthocyanins as well.

The use of numerous potential food plants as commercial sources of anthocyanins is limited by the availability of raw material, as well as by economic considerations. Some colored grains, such as blue/purple maize, blue/purple wheat, blue barley, black rice, as well as black soybean, hold promise as nutraceutical foods. Cereal processing can generate a large amount of anthocyanins-rich by-products at low cost given that anthocyanins are located in the outer layers of the grain, which could be separated. Although poorly represented in the diet, at present, colored grains are used for making blue or pink tortillas [Mora-Rochín et al., 2016], pink cookies [Žilić et al., 2016], multigrain bread [Bartl et al., 2015], and tea. Possibility of wide application of colored grains, especially in the bakery and confectionery industry, reflects the need to better understand their anthocyanins profile, as well as behavior of anthocyanins in different conditions of grain processing. Therefore, the aim of this study was to determine the composition of anthocyanins in the grain of blue popping maize, deep purple maize, purple wheat, and black soybean. In order to determine with certainty the presence of acylated derivatives in the colored grains, alkaline hydrolysis was used to separate aliphatic or/and aromatic acids from anthocyanins. Hence, the aim was to determine the effect of the applied alkaline hydrolysis method for the identification of phenolic compounds on the content of acylated, as well as non-acylated derivatives in anthocyanin extracts.

\section{MATERIALS AND METHODS}

\section{Plant materials}

The genotype of blue popping maize, deep purple maize, purple wheat, and black soybean used in this study was obtained from the Maize Research Institute Zemun Polje (MRIZP) gene bank (Serbia). The grains of blue aleurone popping maize genotype were collected in the vicinity of Kragujevac (Central part of Serbia). Deep purple standard-grain maize was bought recently at the market from local farmers from the vicinity of Santiago (Chile). The purple color of its grain, almost black, comes from a combination of anthocyanin genes for blue pericarp and blue aleurone. The used wheat cultivar Indigo, with light purple color of aleurone, was released in United Kingdom. Soybean variety Black Tokyo, with black seed coat and yellow cotyledons, originates from Japan. Although black soybean is native to tropical Asia and Southeast Asia where it is widely used as a basic ingredient of food, Black Tokyo variety has been used extensively for the past five years in the breeding process of the Maize Research Institute, Serbia.

\section{Analytical procedures}

\section{Chemicals and reagents}

All chemicals and solvents were of the HPLC or analytical grade. Potassium persulfate (dipotassium peroxodisulfate), 2,2'-azino-bis/3-ethylbenzothiazoline-6-sulfonic acid (ABTS), delfinidin-3-glucoside (De-3-Glu), cyanidin-3,5-diglucoside (Cy-3,5-diGlu), cyanidin-3-glucoside (Cy-3-Glu), petunidin-3-glucoside (Pt-3-Glu), pelargonidin-3-glucoside (Pg-3-Glu), malvidin-3-glucoside (Mv-3-Glu), and formic acid were purchased from Sigma-Aldrich (Steinheim, Germany). Methanol and acetonitrile were purchased from J.T. Baker (Avantor, The Netherlands). Hydrochloric acid and potassium hydroxide were purchased from Merck (Darmstad, Germany). Ultrapure water was used throughout the experiments (LaboStar PRO TWF, Evaqua Water Technology, Germany).

\section{Analysis of total anthocyanins}

Anthocyanins were extracted from 150, 40, 400, and $150 \mathrm{mg}$ of blue popping maize, deep purple maize, purple wheat, and black soybean, respectively, by mixing with $10 \mathrm{~mL}$ of methanol acidified with $1 \mathrm{M} \mathrm{HCl}(85: 15$, v/v) and shaking for $30 \mathrm{~min}$ at ambient temperature. The crude extract was centrifuged at $10,000 \mathrm{rpm}$ for $5 \mathrm{~min}$ at $4^{\circ} \mathrm{C}$. Absorbance was measured at 535 and $700 \mathrm{~nm}$ to detect anthocyanins. A UV/ VIS spectrophotometer Agilent 8453 with Peltier Temperature Controller Agilent 89090A was used. Using the molar extinction coefficient of $25965 \mathrm{Abs} / \mathrm{M} \times \mathrm{cm}$ and a molecular weight of $449.2 \mathrm{~g} / \mathrm{mol}$ the content of anthocyanins was calculated and expressed as mg of cyanidin 3-glucoside equivalent (CGE) per kg of dry matter (d.m.) [Lee et al., 2005]. 
Analysis of total antioxidant capacity

The antioxidant capacity of maize, wheat, and soybean flour were measured according to the QUENCHER method described by Serpen et al. [2008], using $7 \mathrm{mM}$ aqueous solution of ABTS (2,2-azino-bis/3-ethil-benothiazoline-6-sulphonic acid) with $2.45 \mathrm{mM} \mathrm{K}_{2} \mathrm{O}_{8} \mathrm{~S}_{2}$ as the stock solution. The working solution of $\mathrm{ABTS}^{\cdot+}$ was obtained by diluting the stock solution in water/ethanol $(50: 50, \mathrm{v} / \mathrm{v})$. Depending on the sample, 6 to $9 \mathrm{mg}$ of the flour were mixed with $20 \mathrm{~mL}$ of $\mathrm{ABTS}^{\cdot+}$ working solution, and the mixture was rigorously shaken for $25 \mathrm{~min}$. After centrifugation at $9200 \times \mathrm{g}$ for $5 \mathrm{~min}$ at $4^{\circ} \mathrm{C}$ the absorbance was measured at $734 \mathrm{~nm}$. A UV/VIS spectrophotometer Agilent 8453 with Peltier Temperature Controller Agilent 89090A was used. The total antioxidant capacity was expressed as Trolox equivalent antioxidant capacity (TEAC) in mmol of Trolox per kg of d.m.

\section{Analysis of individual anthocyanins by HPLC}

Individual anthocyanins were determined by HPLC analysis from the prepared extracts after their filtration through a nylon syringe filter of $0.45 \mu \mathrm{m}$. Pure anthocyanin compounds such as De-3-Glu, Cy-3,5-diGlu, Cy-3-Glu, Pt-3-Glu, Pg-3-Glu, and Mv-3-Glu were used as references for concentration, retention time, and UV characteristic. Identified non-acylated anthocyanin peaks were confirmed and quantified using the Thermo Scientific Dionex Chromeleon 7.2. chromatographic software and the results were expressed as $\mu \mathrm{g}$ per $\mathrm{g}$ of $\mathrm{d} . \mathrm{m}$. Stock standard solutions were prepared in methanol acidified with $1 \mathrm{M} \mathrm{HCl}(85: 15, \mathrm{v} / \mathrm{v})$ at a concentration of $1.0 \mathrm{mg} / \mathrm{mL}$. The working solutions were prepared by diluting the stock solutions with acidified methanol to concentrations of 5.0, 10.0, 20.0, 40.0, 50.0, and $100.0 \mu \mathrm{g} / \mathrm{mL}$. The HPLC analysis was carried out with the HPLC-DAD system (Thermo Scientific Ultimate 3000). Chromatograms were obtained at $530 \mathrm{~nm}$ after injection of $10 \mu \mathrm{L}$ of the sample. Separation was performed on a Thermo Scientific Hypersil GOLD aQ C18 column (150 mm $\times$ $4.6 \mathrm{~mm}$, i.d., $3 \mu \mathrm{m}$ ) using a linear gradient elution program with a mobile phase containing solvent $\mathrm{A}$ (formic acid/ $\mathrm{H}_{2} \mathrm{O}$, 1:99, v/v), and solvent B (formic acid/acetonitrile, 1:99, v/v) at a flow rate of $0.7 \mathrm{~mL} / \mathrm{min}$ and the column oven temperature of $30^{\circ} \mathrm{C}$. The following gradient was established: linear gradient elution from $10 \%$ B to $30 \% \mathrm{~B}, 0-30$ min; linear gradient elution from $30 \% \mathrm{~B}$ to $100 \% \mathrm{~B}, 30-35 \mathrm{~min}$; isocratic elution of $100 \%$ B, 35-38 min; linear gradient elution from $100 \%$ B to $10 \% \mathrm{~B}, 38-40 \mathrm{~min}$; isocratic elution of $10 \% \mathrm{~B}, 40-45 \mathrm{~min}$.

In order to confirm the presence of acylated forms of anthocyanin, alkaline hydrolysis of the extracts was carried out according to the method described by Pedreschi \& Cisneros-Zevallos [2007] with slight modifications. $150 \mu \mathrm{L}$ of $10 \% \mathrm{KOH}$ was necessary for the appearance of a blue color in $1 \mathrm{~mL}$ of extract of anthocyanins. All hydrolysates were kept in darkness for $10 \mathrm{~min}$. Then, $6 \mathrm{M} \mathrm{HCl}$ was added to the solution until stable red color appeared (a total of about $50 \mu \mathrm{L}$ ). After centrifugation at $10,000 \mathrm{rpm}$ for $3 \mathrm{~min}$ at $4^{\circ} \mathrm{C}$ and filtration through a nylon syringe filter of $0.45 \mu \mathrm{m}$, the supernatants were used for the analysis of anthocyanins according to the HPLC method described above. The content of acylated derivatives of cyanidin and pelargonidin was calculated af- ter confirmation of their presence in extracts before and after alkaline hydrolysis by mass spectrometry. After comparing the data obtained with HPLC and HPLC-MS analysis, the acylated derivatives were quantified using HPLC peak area values (mAU*min) and external standard curves for Cy-3-Glu and Pg-3-Glu. The content of acylated derivatives of cyanidin and pelargonidin was calculated as equivalent to their glucoside forms and expressed as $\mu \mathrm{g}$ per $\mathrm{g}$ of d.m.

\section{Analysis of individual anthocyanins by HPLC-MS}

As indicated above, anthocyanin compounds were determined by comparison of the spectroscopic and chromatographic properties with those of authentic anthocyanin standards (De-3-Glu, Cy-3-Glu, Pt-3-Glu, Pg-3-Glu, and Mal-3-Glu). The remaining compounds were tentatively identified using a combination of the retention time, peak spectra, mass-to-charge ratio and pattern of fragmentation. Samples were injected into a Waters HPLC system consisting of 1525 binary pumps, a thermostat, and a 717+ autosampler connected to the Waters 2996 diode array and an EMD 1000 single quadrupole detector with an ESI probe (Waters, Milford, USA). Separation of anthocyanins was performed on a Symmetry C-18 RP column $125 \times 4 \mathrm{~mm}$ packed with $5 \mu \mathrm{m}$ diameter particles (Waters, Milford, MA, USA) and connected to an appropriate guard column. Two mobile phases, A (1\% formic acid) and B (acetonitrile), were used at a flow rate of $1 \mathrm{~mL} / \mathrm{min}$ with the following gradient profile: initial $10 \% \mathrm{~B}$; in 30 min linear rise to $30 \% \mathrm{~B}$; from $30-35 \mathrm{~min}$ to $50 \% \mathrm{~B}$; in next $10 \mathrm{~min}$ return to $10 \% \mathrm{~B}$ with additional $5 \mathrm{~min}$ of equilibration time. A post column flow splitter (ASI, Richmond, CA, USA) with a 5/1 split ratio was used to obtain the optimal mobile phase inflow for the ESI probe. For LC/MS analysis, signals for each compound were detected in the positive ESI single ion recording (SIR) mode with the following parameters: capillary voltage of $2.5 \mathrm{kV}$, cone voltage of $-30 \mathrm{~V}$, extractor and RF lens voltages of 3.0 and $0.2 \mathrm{~V}$, respectively. Source and desolvation temperatures were $130^{\circ} \mathrm{C}$ and $400^{\circ} \mathrm{C}$, respectively, with $\mathrm{N}_{2}$ gas flow of $500 \mathrm{~L} / \mathrm{h}$. Data acquisition and spectral evaluation for peak confirmation were carried out by the Waters Empower 2 Software (Waters, Milford, USA).

\section{Statistical analyses}

All analyses were done in duplicate per genotype and the results were statistically analyzed using the Statistica software version 5.0 (StatSoft Co., Tulsa, OK, USA). The analytical data are reported as the mean \pm standard deviation. Significance of differences between genotypes means were analyzed by Tukey's (HSD) test. Differences were considered significant at $p<0.05$.

\section{RESULTS AND DISCUSSION}

\section{Total anthocyanins content and antioxidant capacity}

The content of total anthocyanins in the grain of blue popping maize, deep purple maize, purple wheat, and black soybean, as well as the antioxidant capacity of the grains are shown in Table 1. According to our study, the content of total anthocyanins varied significantly between colored grains. 
Blue popping maize $(\mathrm{A})$
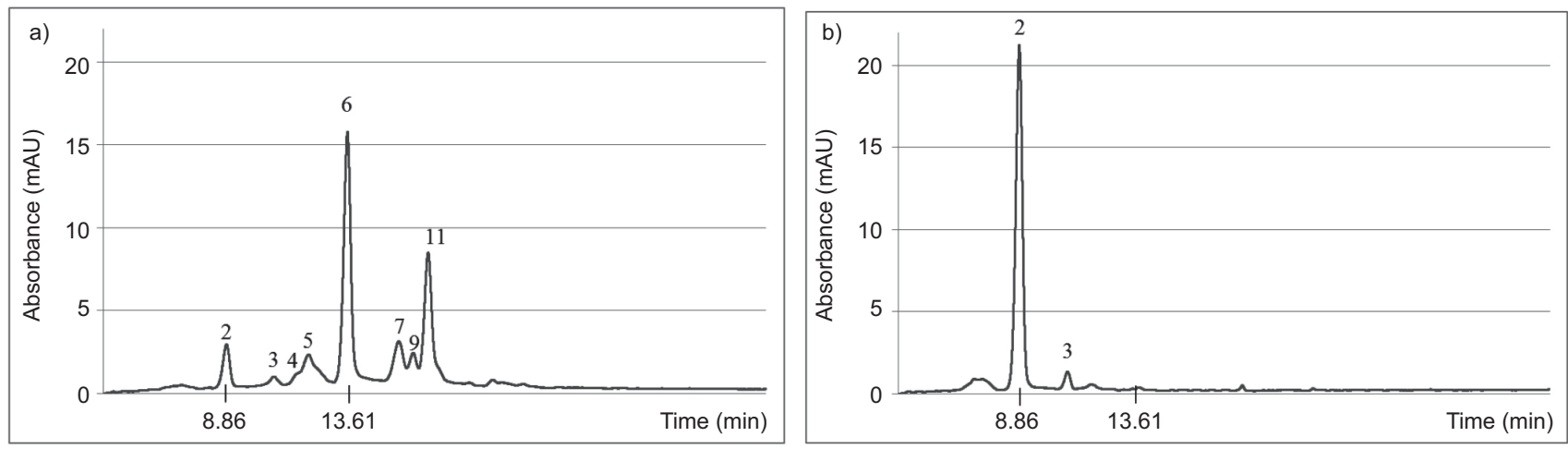

Chilean deep purple maize (B)
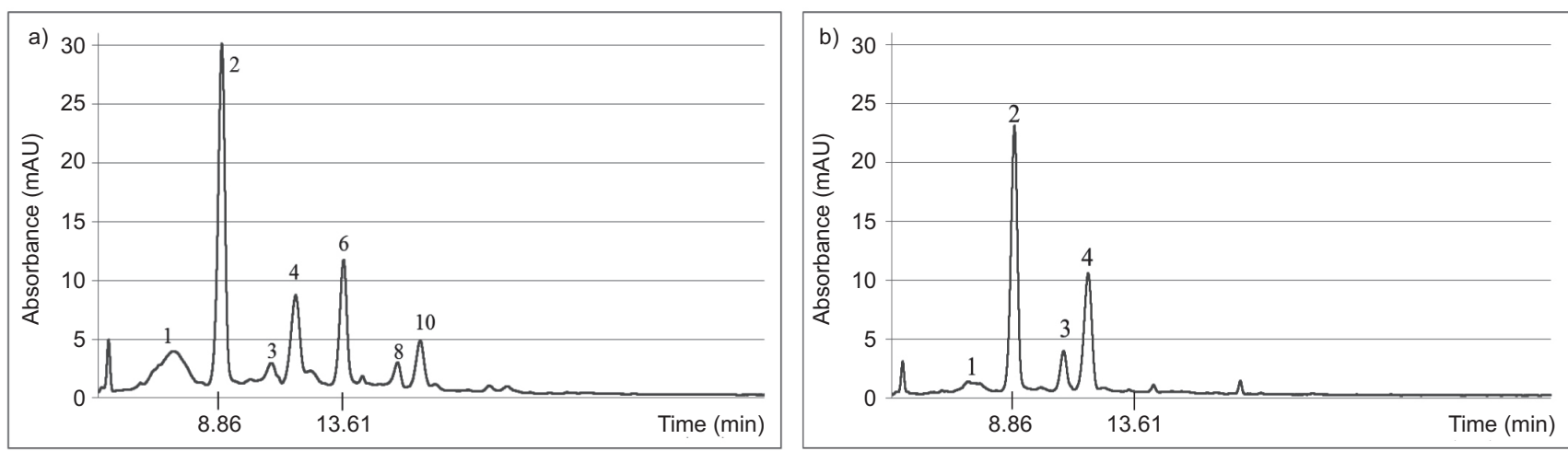

Purple wheat (C)
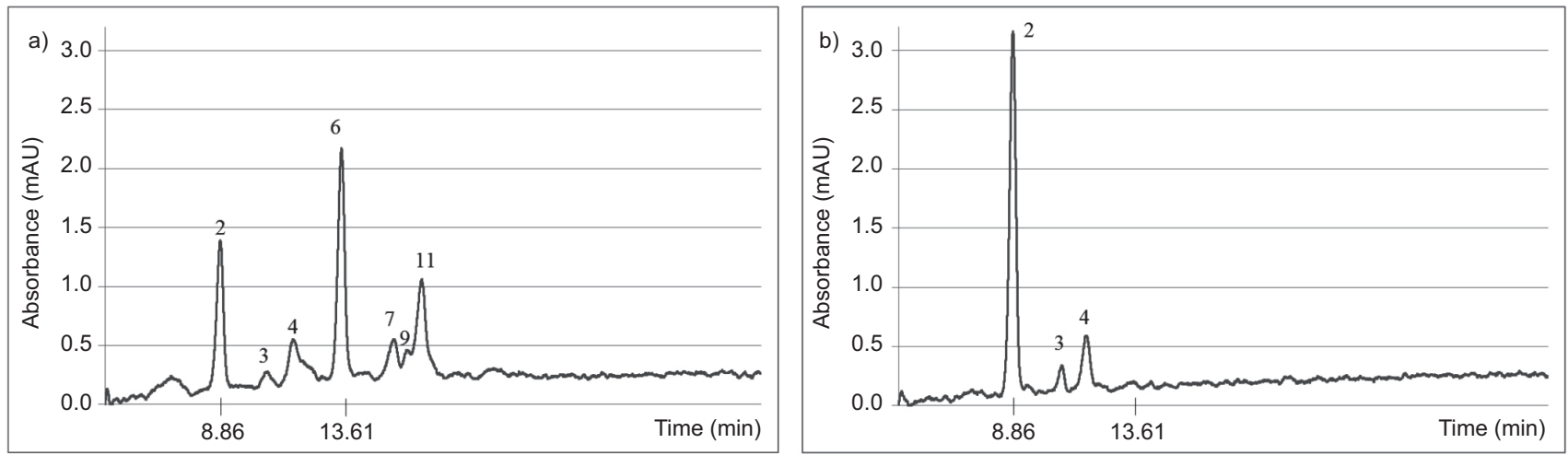

Black soybean (D)
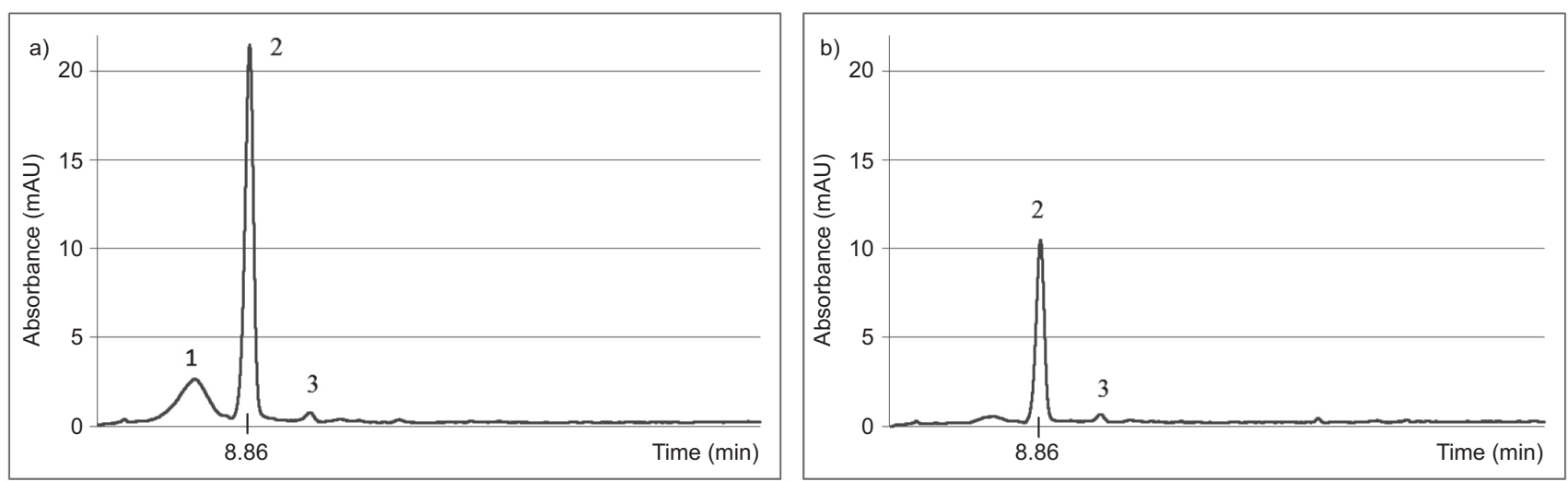

FIGURE 1. Chromatogram at $530 \mathrm{~nm}$ corresponding to A - blue popping maize, B - Chilean deep purple maize, C - purple maize, and D - black soybean extracts a) before and b) after alkaline hydrolysis. The peak numbers show the major anthocyanins that are identified in Table 2. 
TABLE 1. Content of anthocyanins and antioxidant capacity of colored grains.

\begin{tabular}{lcc}
\hline Sample & $\begin{array}{c}\text { Total anthocyanins } \\
\text { (mg CGE/kg d.m.) }\end{array}$ & $\begin{array}{c}\text { Antioxidant } \\
\text { capacity of flour } \\
\text { (mmol Trolox Eq/kg d.m) }\end{array}$ \\
\hline $\begin{array}{l}\text { Blue popping } \\
\text { maize }\end{array}$ & $907.51 \pm 9.8^{\mathrm{b}}$ & $37.62 \pm 3.39^{\mathrm{d}}$ \\
$\begin{array}{l}\text { Deep purple } \\
\text { maize }\end{array}$ & $4988.90 \pm 450.1^{\mathrm{a}}$ & $230.88 \pm 1.83^{\mathrm{a}}$ \\
Purple wheat & $91.72 \pm 4.3^{\mathrm{d}}$ & $41.13 \pm 0.80^{\mathrm{cd}}$ \\
Black soybean & $583.42 \pm 26.3^{\mathrm{c}}$ & $92.74 \pm 1.47^{\mathrm{b}}$ \\
\hline
\end{tabular}

Means followed by the same letter within the same column are not significantly different, according to Tukey's test ( $p=95 \%)$.

Chilean deep purple maize had the highest content of total anthocyanins reaching as much as $4988.90 \mathrm{mg} \mathrm{CGE} / \mathrm{kg}$ d.m. It was higher than that in chokeberry (Aronia melonocarpa E.) (4341 mg CGE/kg d.m.) [Jakobek et al., 2007] and significantly higher than in other berry fruits [Jakobek et al., 2007]. In comparison with the blue popping maize, purple wheat and black soybean, Chilean maize had 5.5, 54.4, and 8.5 times higher content of total anthocyanins, respectively. However, the antioxidant capacity of Chilean deep purple maize was higher by only 5.5 and 2.5 times than that of purple wheat and black soybean, respectively. Having that in mind, it can be concluded that the anthocyanins contained in the grain-matrix of deep purple maize exhibited a lower antioxidant capacity compared to other bioactive compounds present in grains of wheat and soybean. The same applies to anthocyanins in the grain of blue popping maize. In the grain of this maize, the total anthocyanins content of $907.51 \mathrm{mg}$ CGE $/ \mathrm{kg}$ d.m. was higher by 10 and 1.5 times, while its antioxidant capacity of $37.62 \mathrm{mmol}$ TEAC/kg d.m. was even lower by 1.1 and 2.5 times compared to the values reported in the grain of wheat and soybean, respectively. Among other things, this can be a consequence of a synergistic, additive or antagonistic interaction that arises from the coexistence of anthocyanins and numerous other antioxidant compounds in the grains. For instance, it has been established that catechin, which is relatively inefficient at inhibiting linoleic acid oxidation, regenerates the highly efficient antioxidant Mal-3-Glu and, at a lower extent, peonidin-3-glucoside (Pn-3-Glu). The Mal-3-Glu recycling by catechin strongly increased the antioxidant efficiency of these two antioxidants [Rossetto et al., 2002]. Such a high antioxidant capacity of black soybean can be a consequence of this catechin/anthocyanin interaction. As previously established [Žilić et al., 2013], the soybean variety Black Tokio, used in this study, had a high content of catechin in seed coat, accounting for over $2000 \mu \mathrm{g} / \mathrm{g} \mathrm{d}$.m. Contrary to the above, the study of Hidalgo et al. [2010] has shown that DPPH scavenging activities were reduced in combinations of individual anthocyanins by promoted antagonistic effects.

\section{Composition of anthocyanins, their relative quantitative content, and relationship of acylated and non-acylated forms}

It has been established that small differences in the chemical structure of anthocyanins may have an important im- pact on spectral characteristics and antioxidant properties of the pigments [Kähkönen \& Heinonen, 2003]. Therefore, the composition of anthocyanins in grains was analyzed and HPLC chromatograms at $530 \mathrm{~nm}$ of crude extract are shown in Figures 1A-1D. The results of HPLC and HPLC-MS analysis for anthocyanins are summarized in Tables 2 and 3. The composition and content of anthocyanins in grains after alkaline hydrolysis are shown as well.

\section{Anthocyanins profile of maize grain (blue popping and deep purple standard-grain maize)}

Anthocyanin profiles observed in the grain of blue popping maize and in the grain of deep purple maize were different. Overall, the identified anthocyanins in maize grains were $\mathrm{Dp}, \mathrm{Cy}, \mathrm{Pg}$, and Pn conjugated with glucose, and their acylated forms, including mono- and di-malonyl derivatives (Table 2, Figure 1Aa and 1Ba).

In the grain of blue popping maize, five major anthocyanins were identified, including cyanidin-3-glucoside (Cy-3-Glu; peak 1, m/z 449), pelargonidin-3-glucoside (Pg-3Glu; peak 2, m/z 433), peonidin-3-glucoside (Pn-3-Glu; peak $3 \mathrm{~m} / \mathrm{z}$ 463), cyanidin-3-(malonylglucoside) (Cy-3-Mal-Glu; peaks 4 and 5, m/z 535), and cyanidin-3-(dimalonyl- $\beta$-glucoside) (Cy-3-diMal-Glu; peaks 6, 7 and 8, m/z 621). Pelargonidin-3-(6'-malonylglucoside) (Pg-3-6Mal-Glu, $\mathrm{m} / \mathrm{z} 519)$ and peonidin-3-(6'-malonylglucoside) (Pn-3-6Mal-Glu, m/z 549) were present in traces (Table 2, Figure 1Aa). Some derived compounds had similar spectroscopic properties and the same mass-to-charge ratio, but different retention times (Table 2). This could be explained by the presence of isomers of anthocyanins, hence two isomers of Cy-3-Mal-Glu and three isomers of Cy-3-diMal-Glu were identified. By comparing with published data [Wu \& Prior, 2005], isomers of Cy-3-Mal-Glu, peaks 4 and 5, sharing the same MS spectra at different retention times of 12.08 and $13.61 \mathrm{~min}$, were identified as cyanidin-3-(3'-malonylglucoside) (Cy-3-3Mal-Glu) and cyanidin-3-(6'-malonylglucoside) (Cy-3-6Mal-Glu), respectively. In the grain of two landraces of blue Mexican maize, Mora-Rochín et al. [2016] reported the presence of three isomers of Cy-3-Mal-Glu, two isomers of cyanidin-3-(succinylglucoside) (Cy-3-Suc-Glu), and two isomers of cyanidin-3-(disuccinylglucoside) (Cy-3-diSuc-Glu). Unlike these studies, the previous research of Žilic et al. [2012] showed the presence of two di-glucosides (Cy-3,5-diGlu and Pg-3,5-diGlu) in the total of 10 anthocyanins identified in the grain of blue popping maize. The most abundant anthocyanins in the grain of blue popping maize used in this study were Cy-3-6Mal-Glu (peak 5) and one of the isomers of Cy-3-diMal-Glu (peak 8) accounting for 41.01 and $23.06 \%$ of the total peaks area of anthocyanins, respectively. These results are consistent with the previous research of Salinas-Moreno et al. [2012] for blue/purple grain of Mexican maize. In our study, the peak area of Cy-3-Glu (peak 4) was 6-fold lower than that of Cy-3-6Mal-Glu. It is evident that acylated forms of anthocyanins were dominant in the grain of blue popping maize. Furthermore, they accounted for $85 \%$ of the total peaks area of all detected anthocyanins. According to the research of Urias-Lugo et al. [2015], acylation affects the reduction of cancer cell viability in mammary glands, 
TABLE 2. Anthocyanins composition in grains of blue popping maize, deep purple maize, purple wheat, and black soybean. Chromatographic characteristics of peaks in Figure 1A-1D.

\begin{tabular}{|c|c|c|c|c|c|}
\hline Peak & $\begin{array}{c}\mathrm{t}_{\mathrm{R}} \\
(\mathrm{min})\end{array}$ & $\begin{array}{l}\text { Area }(\%) \\
(530 \mathrm{~nm}) \\
\end{array}$ & $\begin{array}{l}{\left[\mathrm{M}^{+}\right]} \\
(\mathrm{m} / \mathrm{z}) \\
\end{array}$ & $\begin{array}{c}\mathrm{MS} / \mathrm{MS} \\
(\mathrm{m} / \mathrm{z})\end{array}$ & Identity \\
\hline \multicolumn{6}{|c|}{ Blue popping maize } \\
\hline \multicolumn{6}{|c|}{ Before alkaline hydrolysis } \\
\hline 2 & 8.87 & 6.68 & 449 & 287 & Cyanidin 3-glucoside \\
\hline 3 & 10.73 & 1.40 & 433 & 271 & Pelargonidin 3-glucoside \\
\hline 4 & 11.70 & 1.74 & 463 & 301 & Peonidin 3-glucoside \\
\hline 5 & 12.08 & 6.14 & 535 & 287 & $\begin{array}{c}\text { Cyanidin } \\
\text { 3-(3'-malonylglucoside) }\end{array}$ \\
\hline 6 & 13.61 & 41.01 & 535 & 287 & $\begin{array}{c}\text { Cyanidin } \\
\text { 3-(6'-malonylglucoside })^{1}\end{array}$ \\
\hline \multirow[t]{2}{*}{7} & 15.63 & 9.73 & 621 & $438 / 287$ & $\begin{array}{c}\text { Cyanidin 3-(dimalonyl- } \\
\beta \text {-glucoside })^{2}\end{array}$ \\
\hline & 15.71 & trace & 519 & 303 & $\begin{array}{c}\text { Pelargonidin } \\
\text { 3-(6'-malonylglucoside) }\end{array}$ \\
\hline 9 & 16.19 & 5.00 & 621 & $438 / 287$ & $\begin{array}{c}\text { Cyanidin 3-(dimalonyl- } \\
\beta \text {-glucoside })^{2}\end{array}$ \\
\hline 10 & 16.60 & trace & 549 & 301 & $\begin{array}{c}\text { Peonidin } \\
\text { 3-(6'-malonylglucoside) }\end{array}$ \\
\hline 11 & 16.77 & 23.06 & 621 & $438 / 287$ & $\begin{array}{c}\text { Cyanidin 3-(dimalonyl- } \\
\beta \text {-glucoside })^{2}\end{array}$ \\
\hline \multicolumn{6}{|c|}{ After alkaline hydrolysis } \\
\hline 2 & 8.87 & 84.95 & 449 & 287 & Cyanidin 3-glucoside \\
\hline 3 & 10.73 & 3.72 & 433 & 271 & Pelargonidin 3-glucoside \\
\hline
\end{tabular}

\section{Deep purple maize}

Before alkaline hydrolysis

\begin{tabular}{cccccc}
\hline 1 & 6.99 & 13.79 & 465 & 303 & Delphinidin 3-glucoside \\
2 & 8.86 & 35.22 & 449 & 287 & Cyanidin 3-glucoside \\
3 & 10.79 & 3.90 & 433 & 271 & Pelargonidin 3-glucoside \\
4 & 11.74 & 12.73 & 463 & 301 & $\begin{array}{c}\text { Peonidin 3-glucoside } \\
\text { Cyanidin }\end{array}$ \\
6 & 13.61 & 14.38 & 535 & 287 & $\begin{array}{c}\text { 3-(6'-malonylglucoside) } \\
\text { Pelargonidin }\end{array}$ \\
8 & 15.71 & 3.17 & 519 & 303 & $\begin{array}{c}\text { 3-(6'-malonylglucoside) } \\
\text { Peonidin }\end{array}$ \\
10 & 16.60 & 6.09 & 549 & 301 & 3-(6'-malonylglucoside) \\
\hline
\end{tabular}

\begin{tabular}{cccccc}
\hline \multicolumn{5}{c}{ After alkaline hydrolysis } \\
\hline 1 & 6.99 & 4.95 & 465 & 303 & Delphinidin 3-glucoside \\
2 & 8.86 & 51.96 & 449 & 287 & Cyanidin 3-glucoside \\
3 & 10.79 & 8.08 & 433 & 271 & Pelargonidin 3-glucoside \\
4 & 11.74 & 27.43 & 463 & 301 & Peonidin 3-glucoside \\
\hline
\end{tabular}

Purple wheat

\begin{tabular}{cccccc}
\hline \multicolumn{5}{c}{ Before alkaline hydrolysis } \\
\hline 2 & 8.86 & 18.17 & 449 & 287 & Cyanidin 3-glucoside \\
3 & 10.73 & 2.58 & 433 & 271 & Pelargonidin 3-glucoside \\
4 & 11.71 & 8.76 & 463 & 301 & Peonidin 3-glucoside \\
6 & 13.61 & 31.08 & 535 & 287 & 3-(6'-malonylglucoside) \\
\hline
\end{tabular}

\begin{tabular}{|c|c|c|c|c|c|}
\hline \multicolumn{6}{|c|}{ Before alkaline hydrolysis } \\
\hline 7 & 15.64 & 8.15 & 621 & $438 / 287$ & $\begin{array}{c}\text { Cyanidin 3-(dimalonyl- } \\
\beta \text {-glucoside) }{ }^{2}\end{array}$ \\
\hline 8 & 15.71 & trace & 519 & 303 & $\begin{array}{c}\text { Pelargonidin } \\
\text { 3-(6'-malonylglucoside) }\end{array}$ \\
\hline 9 & 16.19 & 3.58 & 621 & $438 / 287$ & $\begin{array}{c}\text { Cyanidin 3-(dimalonyl- } \\
\beta \text {-glucoside })^{2}\end{array}$ \\
\hline 10 & 16.60 & trace & 549 & 301 & $\begin{array}{l}\text { Peonidin } \\
\text { 3-(6'-malonylglucoside) }\end{array}$ \\
\hline 11 & 16.75 & 19.08 & 621 & $438 / 287$ & $\begin{array}{c}\text { Cyanidin 3-(dimalonyl- } \\
\beta \text {-glucoside })^{2}\end{array}$ \\
\hline \multicolumn{6}{|c|}{ After alkaline hydrolysis } \\
\hline 2 & 8.86 & 82.03 & 449 & 287 & Cyanidin 3-glucoside \\
\hline 3 & 10.79 & 4.92 & 433 & 271 & Pelargonidin 3-glucoside \\
\hline 4 & 11.78 & 12.99 & 463 & 301 & Peonidin 3-glucoside \\
\hline \multicolumn{6}{|c|}{ Black soybean } \\
\hline \multicolumn{6}{|c|}{ Before alkaline hydrolysis } \\
\hline 1 & 6.99 & 26.71 & 465 & 303 & Delphinidin 3-glucoside \\
\hline 2 & 8.86 & 69.30 & 449 & 287 & Cyanidin 3-glucoside \\
\hline 3 & 10.79 & 1.74 & 433 & 271 & Pelargonidin 3-glucoside \\
\hline \multicolumn{6}{|c|}{ After alkaline hydrolysis } \\
\hline 2 & 8.86 & 87.25 & 449 & 287 & Cyanidin 3-glucoside \\
\hline 3 & 10.79 & 3.10 & 433 & 271 & Pelargonidin 3-glucoside \\
\hline
\end{tabular}

${ }^{1-2}$ Compounds with identical $\mathrm{m} / \mathrm{z}$ ratio within superscript.

liver, colon, and prostate. These authors point out that an appropriate extraction method of maize anthocyanins must be selected to obtain a high yield of Cy-3-Mal-Glu more than only Cy-3-Glu. Taking into account the high level of Cy-3-Mal-Gly in old blue popping maize from Balkan used in this study, and the poor adaptability of colored maize originating from South America to growing conditions in Europe, it can be used in breeding of modern hybrids for temperate areas as a source of genes that play a structural or regulatory role in anthocyanin biosynthesis [Vancetović et al., 2014].

In contrast to the blue popping maize, the glucosidic forms of anthocyanins were dominant in the grain of Chilean deep purple maize. Seven major anthocyanins were identified in the grain of this maize, while different isoforms of certain anthocyanins were not detected. Four of them were glucosides: De-3-Glu (peak 1, m/z 465), Cy-3-Glu (peak 2, $\mathrm{m} / \mathrm{z}$ 449), Pg-3-Glu (peak 3, m/z 433), and Pn-3-Glu (peak $4, \mathrm{~m} / \mathrm{z}$ 463), while three of them were acylated forms: $\mathrm{Cy}$ -3-6Mal-Glu (peak 5, m/z 535), Pg-3-6Mal-Glu (peak 6, $\mathrm{m} / \mathrm{z}$ 519), and Pn-3-6Mal-Glu (peak 7, m/z 549) (Table 2, Figure 1Ba). Cy-3-Glu (peak 2), in terms of peak area, represented the major type of anthocyanin in the grain of Chilean deep purple maize comprising $35.22 \%$ of the total anthocyanins, followed by the acylated Cy-3-Glu (peak 5) that represented $14.38 \%$. Similar composition and mutual relative relation of the present anthocyanins was found by Pedreschi \& Cisneros-Zevallos [2007] in the grain of Andean purple maize, in which $\mathrm{Cy}-3$-Glu and the corresponding acylated 
form represented 44.37 and $26.87 \%$, respectively. In our study, compared with blue popping maize, the relative peak area of Cy-3-Glu and Cy-3-6Mal-Glu presented in the grain of deep purple maize was about 5-fold higher, i.e. 3-fold lower. Taking into account the same comparison, Pn-3-Glu, as well as its corresponding acylated form (peaks 4 and 7) were found in relatively high proportions in the grain of deep purple maize (17.73 and 6.09\% of the total peaks area of anthocyanins, respectively).

\section{Anthocyanins profile of wheat grain}

Purple wheat used in this study had an almost identical anthocyanin profile as the blue popping maize. Cy-3-Glu (peak 1, m/z 449), Pg-3-Glu (peak 2, m/z 433), Pn-3-Glu (peak $3 \mathrm{~m} / \mathrm{z}$ 463), Cy-3-6Mal-Glu (peak 4, m/z 535), three isomers of Cy-3-diMal-Glu (peaks 5, 6 and 7, $\mathrm{m} / \mathrm{z}$ 621), as well as Pg-3-6Mal-Glu and Pn-3-6Mal-Glu in trace were identified (Table 2, Figure 1Ca). In the same purple variety Indigo, Liu et al. [2010] detected only Cy-3-Glu. In turn, using newly developed HPLC-MS method, Bartl et al. [2015] managed to separate and define 19 anthocyanins in the blue wheat and 26 in the purple wheat. As in the grain of popping maize, acylated forms of anthocyanins were dominant in the grain of purple wheat. However, they accounted for about $62 \%$ of the total peak area of anthocyanins that was $23 \%$ lower than their proportion in the grain of blue popping maize. The acyl derivative of anthocyanins viz Cy-3-6Mal-Glu (peak 4) was the most abundant compound in purple wheat accounting for $31.08 \%$ of the total anthocyanins. Other predominant anthocyanins included isomer of Cy-3-diMal-Glu (peak 7), $\mathrm{Cy}$ -3-Glu (peak 1), and Pn-3-Glu that represented 19.08, 18.17, and $8.76 \%$ of the total peaks area of anthocyanins, respectively. Abdel-Aal et al. [2006] identified De-3-Glu and Cy-3-Glu as the major anthocyanins in Canadian blue and purple wheat, respectively. According to the results of these authors, eight of the 10 anthocyanins identified in the grain of purple wheat were acylated by malonic and succinic acid but no acylated anthocyanins were found in the blue wheat.

\section{Anthocyanins profile of soybean}

Three anthocyanins were detected in black soybean. They were De-3-Glu, Cy-3-Glu, and Pg-3-Glu (peaks 1, 2 and 3) (Table 2, Figure 1Da). No acylated anthocyanins were found in the soybean that is consistent with the findings reported by Zhang et al. [2011]. Cy-3-Glu was the major anthocyanin representing $69.30 \%$ of the total peaks area of anthocyanins, followed by De-3-Glu and Pg-3-Glu with 26.71 and 1.74\%, respectively. Interesting, in addition to the three major anthocyanins, in the grain of two black soybean varieties Koh et al. [2014] identified cyanidin, as well as acylated Pg-3-Glu (Pg-3-6Mal-Glu) in trace amounts.

\section{Quantification of anthocyanins}

As shown in Table 3, cyanidin derivatives, in the total amount of $465.2,1460.3,80.1$, and $254.0 \mu \mathrm{g} / \mathrm{g}$ d.m., were predominant anthocyanins in the grain of blue popping maize, Chilean deep purple maize, purple wheat, and black soybean, respectively. Acylated forms of cyanidin derivatives accounted for $431.99,423.09,61.88$, and $0 \mu \mathrm{g} / \mathrm{g}$ d.m., i.e. for about $98,29,71$, and $0 \%$ of the total content, respectively. According to results of Zhao et al. [2008], the total content of cyanidin derivatives in five Chinese purple maize hybrids ranged from 87.1 to $2248.3 \mu \mathrm{g} / \mathrm{g}$ d.m., while the acylated forms constituted between 59.3 to $86.1 \%$ of this content. Small amounts of pelargonidin derivatives were detected in the grain of popping maize, wheat, and soybean, while their total content in the grain of Chilean maize was high ( $330.5 \mu \mathrm{g} / \mathrm{g}$ d.m.). The content of De-3-Glu in this maize was about 4 times higher than that in the grain of soybean, where it was also identified.

If the main anthocyanins are compared with literature data, it can be concluded that the content of $\mathrm{Cy}-3$-Glu and its malonyl derivatives (Cy-3-Mal-Glu) was significantly higher in the grain of blue popping and Chilean deep purple maize than in Mexican blue genotypes where it ranged from 2.6 to $19.8 \mu \mathrm{g} / \mathrm{g}$ and from 3.4 to $26.0 \mu \mathrm{g} / \mathrm{g} \mathrm{d}$ d.m., respectively [Mora-Rochín et al., 2016], and similar to those in the grain of some Chinese purple maize genotypes (12.1 to $916.0 \mu \mathrm{g} / \mathrm{g}$ and 55.0 to $1100.3 \mu \mathrm{g} / \mathrm{g} \mathrm{d}$.m., respectively) [Zhao et al., 2008]. The study of Zhao et al. [2008] is one of the few in which the presence of Cy-3-diMal-Glu in maize grain was reported at a high concentration of 20.0 to $628.4 \mu \mathrm{g} / \mathrm{g} \mathrm{d} . \mathrm{m}$. In our study, the content of the dominant isomer of Cy-3-diMal-Glu, identified in blue popping maize, was $113.50 \mu \mathrm{g} / \mathrm{g}$ d.m., while the content of its two isomers occurring at retention times of 15.63 and 16.19 min was 2.4 and 5.4 times lower, respectively. Although Bartl et al. [2015] identified a large number of anthocyanins in the grains of blue and purple wheat, they measured the low content of Cy-3-Glu in them, only at about 1.0 to $1.7 \mu \mathrm{g} / \mathrm{g} \mathrm{d}$.m. However, our results are comparable with the values obtained by $\mathrm{Ab}$ del-Aal et al. [2006] for the content of Cy-3-Glu amounting to $20.3 \mu \mathrm{g} / \mathrm{g} \mathrm{d} . \mathrm{m}$. in the grain of blue wheat. In turn, two Canadian genotypes of purple wheat were found to contain Cy-3-Glu at $103.0 \mu \mathrm{g} / \mathrm{g}$ [Hosseinian et al., 2008]. In these genotypes, the authors did not identify the presence of malonyl derivatives of cyanidin which, according to our investigations, were dominant in purple wheat with a total content of $50.1 \mu \mathrm{g} / \mathrm{g} \mathrm{d}$.m. Very low content of Cy-3-Mal-Glu at $1.2 \mu \mathrm{g} / \mathrm{g}$ d.m. was measured by Abdel-Aal et al. [2006] in purple Canadian wheat. In the grain of black soybean used in this study, the content of the dominant anthocyanins, $\mathrm{Cy}$ -3-Glu and De-3-Glu, can be compared with those in the seed coat of some Korean genotypes. Namely, the content of $\mathrm{Cy}$ -3-Glu and De-3-Glu in seed coat of 56 genotypes of black soybean ranged from 122 to 12073 and from 0 to $2164 \mu \mathrm{g} / \mathrm{g}$ d.m., respectively [Lee et al., 2016]. Only one anthocyanin, Cy-3-Glu, was detectable in the whole kernel of black soybean by Xu \& Chang [2008a], and its content amounted to $86.3 \mu \mathrm{g} / \mathrm{g} \mathrm{d} . \mathrm{m}$. The same authors in one of their studies indicated the content of $\mathrm{Cy}$-3-Glu in whole grain of black soybean at $356.8 \mu \mathrm{g} / \mathrm{g} \mathrm{d}$ d.m. [Xu \& Chang, 2008b]. As Abdel-Aal et al. [2008] already observed, the variation in anthocyanin content and composition in colored maize, wheat and soybean may be due to the differences between genotypes. Furthermore, Zhao et al. [2008] confirmed that in addition to the variety, growing conditions of the purple maize also influence their anthocyanin content. 
TABLE 3. Content of individual anthocyanins from colored grains extracts before and after alkaline hydrolysis.

\begin{tabular}{|c|c|c|c|c|c|c|c|c|c|}
\hline \multirow{2}{*}{ Compounds* } & \multirow{2}{*}{$t_{R}$} & \multicolumn{2}{|c|}{ Blue popping maize } & \multicolumn{2}{|c|}{ Deep purple maize } & \multicolumn{2}{|c|}{ Purple wheat } & \multicolumn{2}{|c|}{ Black soybean } \\
\hline & & $\mathrm{BAH}$ & AAH & $\mathrm{BAH}$ & AAH & BAH & AAH & $\mathrm{BAH}$ & AAH \\
\hline De-3-Glu & 6.99 & n.d. & n.d. & $518.41 \pm 18.1^{\mathrm{a}}$ & $112.65 \pm 4.7^{\mathrm{b}}$ & n.d. & n.d. & $124.93 \pm 6.3^{b}$ & n.d. \\
\hline Cy-3-Glu & 8.86 & $33.21 \pm 1.1^{\mathrm{g}}$ & $299.53 \pm 11.9^{c}$ & $1037.24 \pm 36.3^{\mathrm{a}}$ & $927.98 \pm 38.9^{b}$ & $18.17 \pm 0.9^{\mathrm{g}}$ & $42.67 \pm 2.2^{\mathrm{fg}}$ & $254.04 \pm 13.9^{\mathrm{d}}$ & $87.25 \pm 2.6^{\mathrm{e}}$ \\
\hline Pg-3-Glu & 10.73 & $11.06 \pm 0.4^{\mathrm{cd}}$ & $20.80 \pm 0.8^{c}$ & $182.25 \pm 6.4^{b}$ & $229.15 \pm 9.6^{\mathrm{a}}$ & $2.58 \pm 0.13^{\mathrm{d}}$ & $4.11 \pm 0.22^{\mathrm{d}}$ & $10.11 \pm 0.55^{\mathrm{cd}}$ & $3.10 \pm 0.09^{\mathrm{d}}$ \\
\hline Cy-3-3Mal-Glu & 12.08 & $45.81 \pm 3.8^{\mathrm{a}}$ & n.d. & n.d. & n.d. & n.d. & n.d. & n.d. & n.d. \\
\hline Cy-3-6Mal-Glu & 13.61 & $203.36 \pm 9.2^{\mathrm{b}}$ & n.d. & $423.09 \pm 14.8^{\mathrm{a}}$ & n.d. & $31.08 \pm 1.6^{\mathrm{c}}$ & n.d. & n.d. & n.d. \\
\hline Cy-3-diMal-Glu & 15.63 & $48.13 \pm 3.1^{\mathrm{a}}$ & n.d. & n.d. & n.d. & $8.15 \pm 0.41^{b}$ & n.d. & n.d. & n.d. \\
\hline Pg-3-6Mal-Glc & 15.71 & trace & n.d. & $148.21 \pm 5.2^{\mathrm{a}}$ & n.d. & trace & n.d. & n.d. & n.d. \\
\hline Cy-3-diMal-Glc & 16.19 & $21.19 \pm 0.9^{\mathrm{a}}$ & n.d. & n.d. & n.d. & $3.58 \pm 0.19^{\mathrm{b}}$ & n.d. & n.d. & n.d. \\
\hline Cy-3-diMal-Glc & 16.77 & $113.50 \pm 4.3^{\mathrm{a}}$ & n.d. & n.d. & n.d. & $19.07 \pm 1.0^{\mathrm{b}}$ & n.d. & n.d. & n.d. \\
\hline \multicolumn{2}{|c|}{ Total anthocyanins } & $476.26 \pm 21.4^{c}$ & $320.33 \pm 8.2^{\mathrm{d}}$ & $2309.20 \pm 80.8^{a}$ & $1269.78 \pm 53.3^{b}$ & $82.63 \pm 4.3^{\mathrm{e}}$ & $46.78 \pm 2.5^{\mathrm{e}}$ & $389.08 \pm 21.4^{\mathrm{cd}}$ & $90.35 \pm 2.7^{\mathrm{e}}$ \\
\hline \multicolumn{10}{|c|}{ Total cyanidin derivatives } \\
\hline Non-acylated & & $33.21 \pm 1.1^{\mathrm{g}}$ & $299.53 \pm 11.9^{\mathrm{c}}$ & $1037.24 \pm 36.3^{\mathrm{a}}$ & $927.98 \pm 38.9^{b}$ & $18.17 \pm 0.9^{g}$ & $42.67 \pm 2.2^{\mathrm{fg}}$ & $254.04 \pm 13.9^{\mathrm{d}}$ & $87.25 \pm 2.6^{\mathrm{e}}$ \\
\hline Acylated & & $431.99 \pm 19.6^{\mathrm{a}}$ & n.d. & $423.09 \pm 14.8^{\mathrm{a}}$ & n.d. & $61.88 \pm 3.2^{\mathrm{b}}$ & n.d. & n.d. & n.d. \\
\hline
\end{tabular}

${ }^{*}$ - $\mu \mathrm{g} / \mathrm{g}$ d.m.; BAH-before alkaline hydrolysis; AAH-after alkaline hydrolisys; n.d.-not detected. Means followed by the same letter within the same row are not significantly different, according to Tukey's test $(p=95 \%)$.

\section{Effects of the applied alkaline hydrolysis method for the identification of phenolic compounds on the content of acylated and non-acylated derivatives in anthocyanin extracts}

According to our results, total degradation of all acylated forms of anthocyanins identified in the grain of blue popping maize, Chilean deep purple maize, and purple wheat occurred during alkaline hydrolysis (Tables 2 and 3, Figure $1 \mathrm{Ab}-1 \mathrm{Cb}$ ). The extreme alkaline environment caused the breakdown of ester bonds and the separation of the acyl groups from the anthocyanins. Hence, acylated derivatives were transformed to non-acylated forms. It has already been indicated that acylated forms can transform to non-acylated forms at the beginning of the anthocyanins degradation [Riaz et al., 2016] under the influence of different conditions. The study of West \& Mauer [2013] has shown that about $68 \%$ of the purified cyanidin 3-6Mal-Glu was lost during storage at $40^{\circ} \mathrm{C}$ and converted primarily to $\mathrm{Cy}-3-\mathrm{Glu}$. According to the latest research of Simić et al. [2018], the proportion of Cy-3-Glu and its acylated derivative in blue popping maize flour, also used in this study, as well as in crumb of bread baked at $230^{\circ} \mathrm{C}$ for $20 \mathrm{~min}$ and its crust amounted to 25 and $75 \%$, 42 , and $58 \%$ and finally 58 and $42 \%$ of the total cyanidin derivatives, respectively. This conversion of cyanidin derivatives probably contributed greatly to the preservation of attractive pinkish color of bread. According to our results, in blue popping maize and purple wheat samples, which had low content of Cy-3-Glu and high content of its malonyl derivatives in grains, about 62 and $40 \%$ of the acylated cyanidin derivatives were transformed into non-acylated ones, respectively. (Table 3). In the case of Chilean deep purple maize and black soybeans, it can be concluded that the applied method sig- nificantly reduced non-acylated forms of anthocyanins. The content of Cy-3-Glu was lower by $65 \%$ after alkaline hydrolysis of the black soybean extract. However, in the case of Chilean deep purple maize, Cy-3-Glu reduction was lower and amounted to about $36 \%$ (Table 3). It can be speculated that the $6 \mathrm{M} \mathrm{HCl}$, which was used after alkaline hydrolysis to achieve a stable red color of extracts, affected the separation of aglycons and degradation of anthocyanin glucosides. After alkaline hydrolysis of soybean and Chilean maize extracts, the content of De-3-Glu was reduced by 100 and $80 \%$, respectively. On the other hand, although the content of the acylated form of pelargonidin was not high in maize and wheat samples, after alkaline hydrolysis of their extracts the content of Pg-3-Glu was increased (Table 3). Pedreschi \& Cisneros-Zevallos [2007], whose modified alkaline hydrolysis method has been applied in this study, quantified anthocyanins only in the non-hydrolyzed samples.

Alkaline hydrolysis was performed under extreme conditions in this study. However, many other authors observed the behavior of anthocyanins under the influence of different $\mathrm{pH}$ conditions. According to results of McDougall et al. [2007], all of the anthocyanins were reduced after pancreatic digestion in the alkaline environment but the acylated forms were notably more stable than the non-acylated ones. There was also a relationship between the type of acylated hydroxycinnamic acid and resistance to pancreatic digestion. The study of Cabrita et al. [2000] revealed that, for some of the anthocyanin-3-glucosides (e.g. malvidin-3-glucoside), the bluish color was rather intense and its stability was relatively high in the alkaline region. As presented in the study of Torskangerpoll \& Andersen [2005], aromatic acylated cyanidin derivatives showed higher color stability than the non-acylated forms at $\mathrm{pH}$ values vary- 
ing from 1.1 to 10.5 during 98 -day period at $10^{\circ} \mathrm{C}$. Contrasting with many reports in the literature, some of them are listed above, the malonyl glycoside forms of the anthocyanins from purple maize pericarp were more susceptible to degradation caused by time (12 weeks) and pH (2.0 to 6.0) than the nonacylated forms [Luna-Vital et al., 2017]. In turn, Howard et al. [2016] reported that acetylated derivatives in blueberry juice were more prone to losses during storage than glycosides, especially in acidified juices.

\section{CONCLUSIONS}

It can be concluded that the blue popping maize, deep purple maize, purple wheat, and black soybean used in this study differ significantly both by composition and by content of individual anthocyanins. The acylated forms of anthocyanins were dominant in the grain of blue popping maize, as well as purple wheat and represented 85 and $62 \%$ of the total peaks area of anthocyanins, respectively. In the grain of Chilean deep purple maize, that was the richest in anthocyanins, the glucosidic forms were dominant. Cy-3-Glu represented the major type of anthocyanin in the grain of deep purple maize constituting $35.22 \%$ of the total peaks area of anthocyanins. Furthermore, no acylated anthocyanins were found in the black soybean. Rich in anthocyanins, colored grains could be used as functional food ingredients that provide health benefits to a large part of human world's population.

The extreme alkaline environment caused the breakdown of the ester bonds, the separation of the acyl groups from the anthocyanins, complete degradation of acylated derivatives, and their partial transformation to its non-acylated parents. On the other hand, partial degradation of glycosides in all samples could be a consequence of the acid that is added to the base hydrolysate. These studies confirm that the applied alkaline hydrolysis method can be used only for the identification of acylated anthocyanins. Moreover, this study confirms the importance of plant sources with a high content of anthocyanins precisely because of their low stability.

\section{ACKNOWLEDGEMENTS}

This study was supported by the Ministry of Education, Science and Technological Development of the Republic of Serbia (Grants no. TR 31069 and OI 173040).

\section{CONFLICT OF INTERESTS}

Authors declare no conflict of interests.

\section{REFERENCES}

1. Abdel-Aal, E.-S.M., Abou-Arab, A.A., Gamel, T.H., Hucl P., Young, J.C., Rabalski, I. (2008). Fractionation of blue wheat anthocyanin compounds and their contribution to antioxidant properties. Journal of Agricultural and Food Chemistry, 56(23), 11171-11177.

2. Abdel-Aal, E.-S.M., Young, J.C., Rabalski, I. (2006). Anthocyanin composition in black, blue, pink, purple, and red cereal grains. Journal of Agricultural and Food Chemistry, 54(130), 4696-4704.
3. Andersen, Ø.M., Jordheim, M. (2010). The anthocyanins. In Ø.M. Andersen, K.R. Markham (Eds.), Flavonoids: Chemistry, Biochemistry and Applications, CRC Press, USA, pp. 472-537.

4. Bartl, P., Albreht, A., Skrt, M., Tremlová, B., Oštádalová, M., Šmejkal, K., Vovk, I., Ulrih, N.P. (2015). Anthocyanins in purple and blue wheat grains and in resulting bread: quantity, composition, and thermal stability. International Journal of Food Sciences and Nutrition, 66(5), 514-519.

5. Cabrita, L., Fossen, T., Andersen Ø.M. (2000). Colour and stability of the six common anthocyanidin 3 -glucosides in aqueous solutions. Food Chemistry, 68(1), 101-107.

6. Cortez, R., Luna-Vital, D.A., Margulis, D., de Mejia, G.E. (2017). Natural Pigments: Stabilization methods of anthocyanins for food applications. Comprehensive Reviews in Food Science and Food Safety, 16(1), 180-198.

7. Giusti, M.M, Wrolstad, R.E. (2003). Acylated anthocyanins from edible sources and their applications in food systems. Biochemical Engineering Journal, 14(3), 217-225.

8. Hidalgo, M., Sánchez-Moreno, C., de Pascual-Teresa, S. (2010). Flavonoid-flavonoid interaction and its effect on their antioxidant activity. Food Chemistry, 121 (3), 691-696.

9. Hosseinian, F.S., Li, W., Beta, T. (2008). Measurement of anthocyanins and other phytochemicals in purple wheat. Food Chemistry, 109(4), 916-924.

10. Howard, L.R., Brownmiller, C., Mauromoustakos, A., Prior R.L. (2016). Improved stability of blueberry juice anthocyanins by acidification and refrigeration. Journal of Berry Research, 6(2), 189-201.

11. Jakobek, L., Šeruga, M., Medvidović-Kosanović, M., Novak, I. (2007). Antioxidant activity and polyphenols of aronia in comparison to other berry species. Agriculturae Conspectus Scientificus, 72(4), 301-306.

12. Kähkönen, P.M., Heinonen, M. (2003). Antioxidant activity of anthocyanins and their aglycons. Journal of Agricultural and Food Chemistry, 51 (3), 628-633.

13. Koh, K., Youn, J.E., Kim, H.-S. (2014). Identification of anthocyanins in black soybean (Glycine $\max$ (L.) Merr.) varieties. Journal of Food Science and Technology-Mysore, 51 (2), 377-381.

14. Kong, J.M., Chia, L.S., Goh, N.K., Chia, T.F., Brouillard, R. (2003). Analysis and biological activities of anthocyanins. Phytochemistry, 64(5), 923-933.

15. Lee, J., Durst, R.W., Wrolstad, R.E. (2005). Determination of total monomeric anthocyanin pigment content of fruit juices, beverages, natural colorants, and wines by the $\mathrm{pH}$ differential method: Collaborative study. Journal of AOAC International, 88(5), 1269-1278.

16. Lee, K.J., Lee, J.-R., Ma, K.-H., Cho, Y.-H., Lee, G.-A., Chung, J.-W. (2016). Anthocyanin and isoflavone contents in Korean black soybean landraces and their antioxidant activities. Plant Breeding and Biotechnology, 4, 441-452.

17. Liu, Q., Qiu, Y., Beta, T. (2010). Comparison of antioxidant activities of different colored wheat grains and analysis of phenolic compounds. Journal of Agricultural and Food Chemistry, 58(16), 9235-9241.

18. Luna-Vital, D., Li, Q., West, L., West, M., de Mejia, E.G. (2017). Anthocyanin condensed forms do not affect color or chemical stability of purple corn pericarp extracts stored under different pHs. Food Chemistry, 232, 639-647. 
19. McDougall, G.J., Fyffe, S., Dobson, P., Stewart, D. (2007). Anthocyanins from red cabbage - stability to simulated gastrointestinal digestion. Phytochemistry, 68(9), 1285-1294.

20. Mora-Rochín, S., Gaxiola-Cuevas, N., Gutiérrez-Uribe, J.A., Milán-Carrillo, J., Milán-Noris, E. M., Reyes-Moreno, C., Serna-Saldivar, S.O., Cuevas-Rodriguez, E.O. (2016). Effect of traditional nixtamalization on anthocyanin content and profile in Mexican blue maize (Zea mays L.) landraces. LWT-Food Science and Technology, 68, 563-569.

21. Pedreschi, R., Cisneros-Zevallos, L. (2007). Phenolic profiles of Andean purple corn (Zea mays L.). Food Chemistry, 100(30), 956-963.

22. Riaz, M., Zia-Ul-Haq, M., Saad, B. (2016). Biosynthesis and stability of anthocyanins. In M. Zia-Ul-Haq, M. Riaz, B. Saad (Eds.), Anthocyanins and Human Health: Biomolecular and Therapeutic Aspects, Springer International Publishing, pp. 71-76.

23. Rossetto, M., Vanzani, P., Mattivi, F., Lunelli, M., Scarpa, M., Rigo, A. (2002). Synergistic antioxidant effect of catechin and malvidin 3-glucoside on free radical-initiated peroxidation of linoleic acid in micelles. Archives of Biochemistry and Biophysics, 408(2), 239-45.

24. Salinas-Moreno, Y., Perez-Alonso, J.J., Vazquez-Carrillo, G., Aragon-Cuevas, F., Velazquez-Cardenas, G.A. (2012). Anthocyanins and antioxidant activity in maize grains (Zea mays L.) of Chalqueño, Elotes Cónicos and Bolita races. Agrociencia, 46(7), 693-706.

25. Serpen, A., Gökmen, V., Pellegrini, N., Fogliano, V. (2008). Direct measurement of the total antioxidant capacity of cereal products. Journal of Cereal Science, 48(3), 816-820.

26. Simić, M., Žilić, S., Šimurina, O., Filipčev, B., Škrobot, D., Vančetović, J. (2018). Effects of anthocyanin-rich popping maize flour on the phenolic profile and the antioxidant capacity of mixbread and its physical and sensory properties. Polish Journal of Food and Nutrition Sciences, 68(40), 299-308.

27. Torskangerpoll, K., Andersen, Ø.M. (2005). Colour stability of anthocyanins in aqueous solutions at various $\mathrm{pH}$ values. Food Chemistry, 89(3), 427-440.

28. Trouillas, P., Sancho-García, J.C., De Freitas, V., Gierschner, J., Otyepka, M., Dangles O. (2016). Stabilizing and modulating color by copigmentation: Insights from theory and experiment. Chemical Reviews, 116(9), 4937-4982.

29. Urias-Lugo, D.A., Heredia, J.D., Muy-Rangel, M.D., ValdezTorres, J.B., Serna-Saldivar, S.O., Gutierréz-Uribe, J.A. (2015). Anthocyanins and phenolic acids of hybrid and native blue maize (Zea mays L.) extracts and their antiproliferative activity in mammary (MCF7), liver (HepG2), colon (Caco 2 and HT29) and prostate (PC3) cancer cells. Plant Foods for Human Nutrition, 70(2), 193-199.

30. Vancetović, J., Žilić, S., Božinović, S., Ignjatović-Micić, D. (2014). Simulating of Top-Cross system for enhancement of an- tioxidants in maize grain. Spanish Journal of Agricultural Research, 12(2), 467-476

31. West, E.M., Mauer, J.L. (2013). Color and chemical stability of a variety of anthocyanins and ascorbic acid in solution and powder forms. Journal of Agricultural and Food Chemistry, 61(17), 4169-4179.

32. Wu, X., Prior, L.R. (2005). Identification and characterization of anthocyanins by high-performance liquid chromatographyelectrospray ionization-tandem mass spectrometry in common foods in the United States: Vegetables, nuts, and grains. Journal of Agricultural and Food Chemistry, 53(8), 3101-3113.

33. Xu, B., Chang, S.K.C. (2008a). Antioxidant capacity of seed coat, dehulled bean, and whole black soybeans in relation to their distributions of total phenolics, phenolic acids, anthocyanins, and isoflavones. Journal of Agricultural and Food Chemistry, 56(18), 8365-8373.

34. Xu, B., Chang, S.K.C. (2008b). Total phenolics, phenolic acids, isoflavones, and anthocyanins and antioxidant properties of yellow and black soybeans as affected by thermal processing. Journal of Agricultural and Food Chemistry, 56(16), 7165-7175.

35. Zhang, R.F., Zhang, F.X., Zhang, M.W., Wei, Z.C., Yang, C.Y., Zhang, Y., Tang, X.J., Deng, Y.Y., Chi, J.W. (2011). Phenolic composition and antioxidant activity in seed coats of 60 Chinese black soybean (Glycine max L. Merr.) varieties. Journal of Agricultural and Food Chemistry, 59(11), 5935-5944.

36. Zhao, C.-L., Yu, Y.-Q., Chen, Z.-J., Wen, G.-S., Wei, F.-G., Zheng, Q., Wang, C.-D., Xiao, X.-L. (2017). Stability-increasing effects of anthocyanin glycosyl acylation. Food Chemistry, 214, $119-128$.

37. Zhao, X., Corrales, M., Zhang, C., Hu, X., Ma, Y., Tausher, B. (2008). Composition and thermal stability of anthocyanins from Chinese purple corn (Zea mays L.). Journal of Agricultural and Food Chemistry, 56(22), 10761-10766.

38. Žilić, S., Akıllıŏglu, G., Serpen, A., Perić, V., Gokmen, V. (2013). Comparisons of phenolic compounds, isoflavones, antioxidant capacity and oxidative enzymes in yellow and black soybeans seed coat and dehulled bean. European Food Research and Technology, 237(3), 409-418.

39. Žilić, S., Kocadağlı, T., Vančetović, J., Gökmen, V. (2016). Effects of baking conditions and dough formulations on phenolic compounds stability, antioxidant capacity and color of cookies made from anthocyanin-rich corn flour. LWT-Food Science and Technology, 65, 597-603.

40. Žilić, S., Serpen, A., Akıllığlu, G., Gökmen, V., Vančetović, J. (2012). Phenolic compounds, carotenoids, anthocyanins and antioxidant capacity of colored maize (Zea mays L.) kernels. Journal of Agricultural and Food Chemistry, 60(5), 1224-1231.

Submitted: 9 October 2018. Revised: 4 and 20 February 2019. Accepted: 28 February 2019. Published on-line: 26 March 2019. 